J. Bangladesh Acad. Sci., Vol. 42, No. 1, 87-97, 2018

\title{
ABSORPTION ENHANCEMENT OF ORGANIC SOLAR CELL USING ALUMINUM OXIDE AS A PHOTONIC CRYSTAL
}

\author{
MD. MEHEDHI HASAN, SHAH ASHIKUR RAHMAN, MD. MAHIDUL HAQUE \\ PRODHAN $^{1^{*}}$ AND A B M HASAN TALUKDER \\ Department of Electrical and Electronic Engineering, University of Dhaka, Dhaka-1000, Bangladesh
}

\begin{abstract}
Enhancement of light absorption in solar cell presents a strong challenge to its overall performance. We analyzed an Organic Solar Cell (OSC) with Photonic Crystal (PC) structure using Finite Difference Time Domain (FDTD) method. Aluminum oxide $\left(\mathrm{Al}_{2} \mathrm{O}_{3}\right)$ has been used as photonic crystal structure and the lattice structure has been chosen to be hexagonal. Absorption enhancement has been observed by changing the height of the Hexagonal Lattice structure (HLS). When height is increased to 0.26 and radius to period ratio (r/a ratio) is set to 0.4 , there is a significant increase of absorption in the middle wavelength region approximately from $463 \mathrm{~nm}$ to $575 \mathrm{~nm}$ and a significant decrease in lower wavelength. As the height is increased further, these changes in absorption begins to increase and at a certain value, these changes begin to reverse. Almost same phenomena occur when r/a ratio is 0.2 and 0.3 taken at approximately same height.
\end{abstract}

Key Words: Organic solar cell, Photonic crystal, Absorption enhancement, Energy pay back time, Guided modes, FDTD method

\section{INTRODUCTION}

The development and utilization of organic solar cells, nowadays, is proved to be a better way to produce clean and renewable energy because of its several advantages including the ease of fabricating them onto large areas of lightweight substrates. The first conceptual organic solar cell, which was developed by Kearns and Calvin in (1958), used magnesium phthalocyanine as organic material between two electrodes (Naichia et al. 2013; David et al. 1958). The Power Conversion Efficiency (PCE) was too low (in the order of $0.1 \%$ or lower) and it could not be increased for more than 20 years (Holger et al. 2004). In 1986, Tang developed bilayer hetero junction OSCs with a PCE of about $1 \%$ which is regarded as a major milestone for OSC (Tang C. et al. 1986; Prodhan et al. 2017; Cheyns et al. 2010; You J. et al. 2013).

The solution process ability of organic semiconductors provides a great potential for low cost (Deepti et al. 2016) fabrication of large area OSCs. Low temperature processing reduces energy consumption during manufacturing. OSCs have capability of decreasing the energy payback time and printing on top of plastic substrates results in

* Corresponding author: < prodhan@du.ac.bd >.

1 Department of Nuclear Engineering, University of Dhaka, Dhaka-1000, Bangladesh. 
applications. Not only having low efficiency compared to silicon solar cells but also the stability of OSCs is a limitation to worldwide commercialization (Vikram et al. 2012). Recently organic solar cell efficiency has been increased to more than $10 \%$ (K. Woods et al. 2013) using bulk hetero junction and tandem cell structure (Nusrat et al. 2017).

Using photonic crystal in OSC can improve efficiency nearly to 70\% (Doo-Hyun et al. 2009). One-dimensional (1-D) photonic crystals can be made of layers deposited or stuck together. Combination of 1-D photonic crystal and dielectric material can increase the effectiveness of absorption (James G. et al. 2009). Two-dimensional 2-D photonic crystals are fabricated by photolithography, or by drilling holes in a suitable substrate. Both 1-D and 2-D photonic crystals (Fig. 1) are used in thin film (Angelo et al. 2012) and ultra-thin film (Emmanuel et al. 2010) solar cells to increase the effectiveness of light trapping and photon lifetime (Emmanuel et al. 2009). Three-dimensional (3-D) photonic crystals (Fig. 1) are made by drilling under different angles, stacking multiple 2-D layers on top of each other.

Indium tin oxide (ITO) is a ternary composition of tin, oxygen and indium. ITO is transparent and conductive and has a high value of conductivity as well as optical property. In solar cell, the main advantage of ITO is that it can be made as thin as possible. PC is usually inserted on the upper ITO electrode (Leo et al. 2014).

By inserting Phenyl-C61-butyricacidmethyl ester (PCBM) and Poly-3-hexylthiophene (P3HT) layer, maximum conversion energy for solar cell is reached to $10 \%$ (Alias et al. 2014). It is a combination of narrow-band donor and fullerene derivate which is a possible approach to efficient organic cells (Schmidt et al. 2015). Performance of P3HT: PCBM is linked with electron to hole mobility ratios (Omar et al. 2013) and it also works as buffer layer (Zurianti et al. 2012). Also, the performance and degradation of bulk heterojunction organic solar cell depends on P3HT: PCBM (Balderramaa et al. 2011)

Poly (3,4-ethylenedioxythiophene)-poly (styrenesulfonate), commonly known as PEDOT: PSS, is a widely used hole transport layer. It is also a spin cast film. It has an aqueous dispersion with a hygroscopic property. It increases the series resistance of the device but decreases fill factor and current.

In this research work, light absorption is
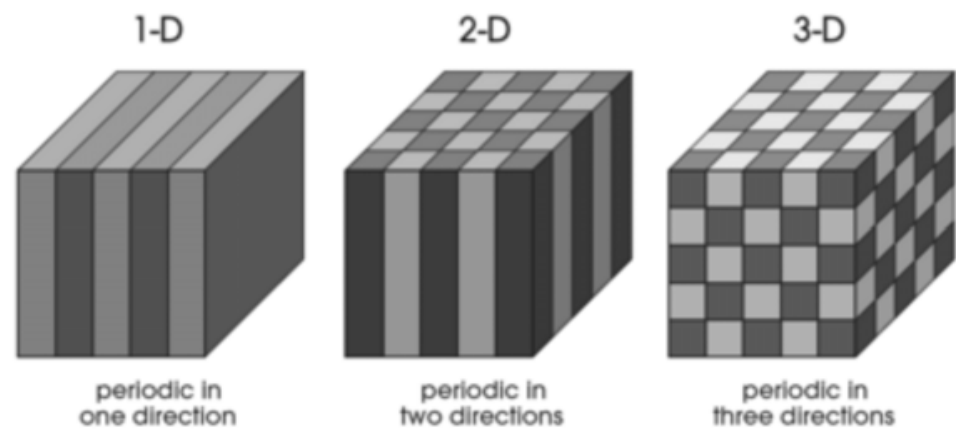

Fig. 1. 1D, 2D, 3D Photonic Crystal [Joannopoulos et al. 2008] 
measured in P3HT: PCBM layer of the designed structure using FDTD simulations. Absorption profiles for OSC with different height and r/a ratio of the PC structure were compared and analyzed with that of flat solar cells.

\section{METHODOLOGY}

In order to analyze the light absorption, the structure shown in Fig. 2 is designed first
In setting up the structure, the geometry of each layer is fixed in terms of XY, YZ, and $\mathrm{ZX}$ dimensional positions. Three monitors are positioned to record the result. Those monitors are used to compare the results for OSC with photonic crystal layer and for flat surface with no extra layer. At first, period and diameter of the hexagonal PC structure are varied with fixed height to observe the absorption enhancement. Then height is varied with fixed period and diameter to

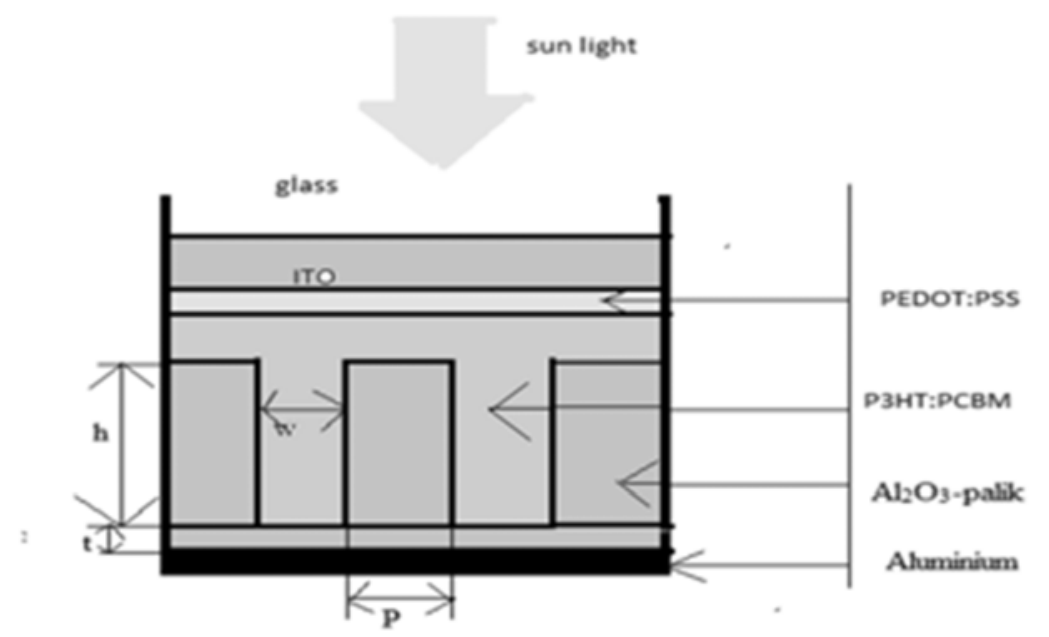

Fig. 2. Organic solar cell with aluminum oxide $\left(\mathrm{Al}_{2} \mathrm{O}_{3}\right)$ as photonic crystal structure [Knowledge base, Lumerical Solution Inc.].

using the FDTD solutions package of observe the absorption enhancement (Fig. 3). Lumerical Inc.

The structure has an aluminum layer at the bottom. Following up is a layer of $\mathrm{Al}_{2} \mathrm{O}_{3}$ adjacent with pillar type structure formed with $\mathrm{Al}_{2} \mathrm{O}_{3}$. A layer of P3HT: PCBM (poly3-hexylthiophene [6,6]-phenyl-C61-butyric acid methyl ester) is employed then, which For every layer, rectangular structure and mesh order of 2 is used. Geometry is different for each layer. Sunlight is not directly used in this setup. Instead a normally plane wave source of wavelength ranging from 400 to $700 \mathrm{~nm}$ is used. acts as a photoactive layer on PEDOT: PSS above of it. Sunlight is allowed to fall on a glass layer at the top of the structure beyond which an ITO layer is incorporated. 


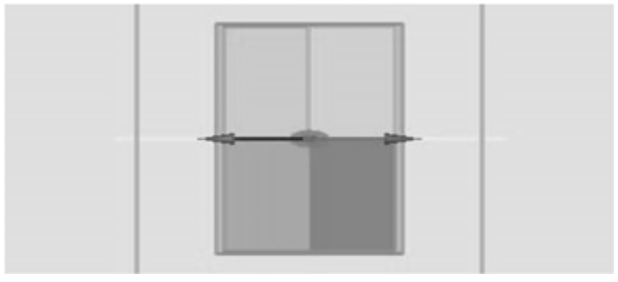

Fig. 3(a)

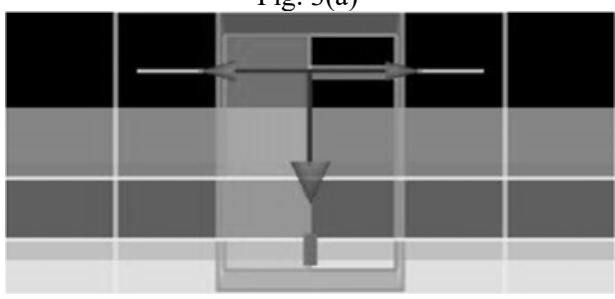

Fig. 3(c)

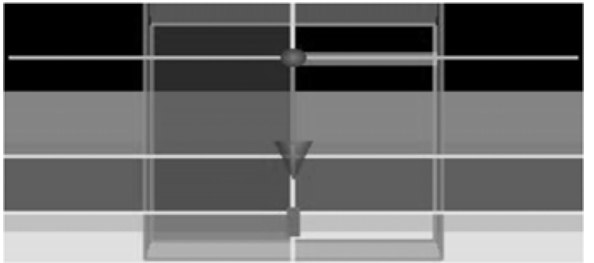

Fig. 3(b)

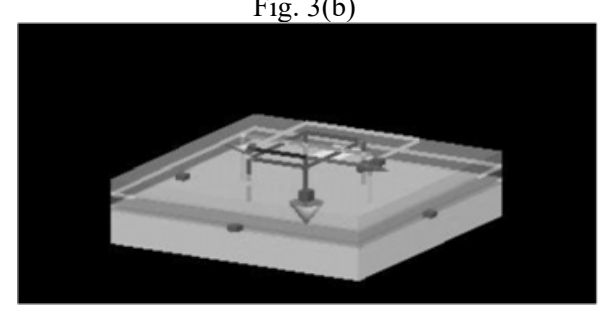

Fig. 3(d)

Fig. 3. Organic Solar cell $2 \mathrm{D}$ hexagonal lattice of photonic crystal are formed in the photoactive layer, (a) XY view, (b) YZ view, (c) ZX view and (d) perspective view.

Fig. 4 shows the normal coordinate view of a plane source.

For calculating the power absorption monitor_3 and monitor_4 is used. Monitor_3 is located boundary between P3HT: PCBM and PEDOT:

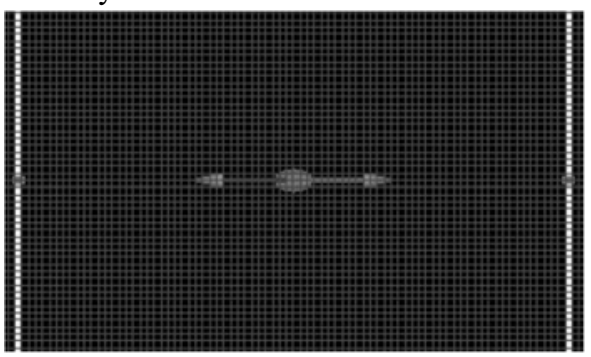

Fig. 4(a)

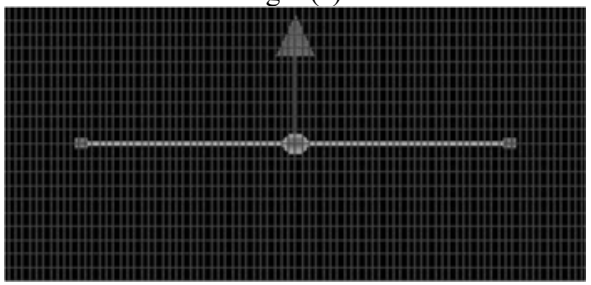

Fig. 4(c)
The absorbed power $\mathrm{P}_{\mathrm{abs}}$ is easily calculated by, $\operatorname{Pabs}(1)=-$ transmission $\quad\left(\right.$ monitor $\left._{3}\right) 1 \quad(-$ transmission (monitor 4$)$ ).

By using monitor 1, monitor 3, monitor 4 power absorption in ITO and PEDOT: PSS

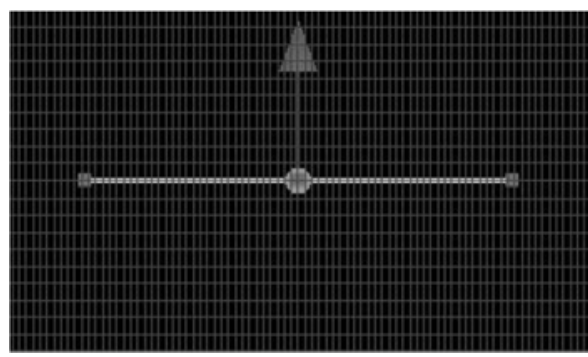

Fig. 4(b)

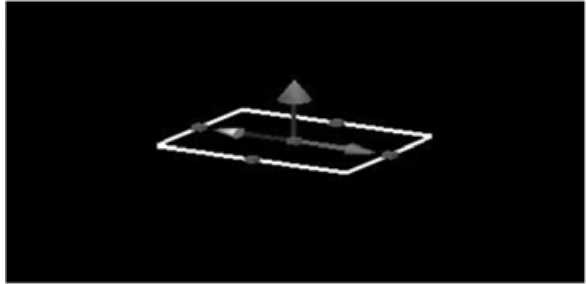

Fig. 4(d)

Fig. 4. (a) XY view (b) YZ view (c) ZX view (d) perspective view.

PEDOT: PSS. Monitor_4 is located at the layer can be calculated. For absorption boundary between $\mathrm{P} 3 \mathrm{HT}$ : PCBM and $\mathrm{Al}_{2} \mathrm{O}_{3}$. profile power monitor is required. In the 
following table (Table-1) the general set up and geometry are shown. with photonic crystal when the period and diameter is fixed to 0.3 micron and 0.46

Table 1. Simulation setup parameters and device geometry

\begin{tabular}{|c|c|c|c|}
\hline & Monitor 1 & Monitor 3 & Monitor 4 \\
\hline Geometry & $\begin{array}{l}x=0, y=0, z=0.2757 \\
x \text { span }=0.138, y \text { span }=0, \\
z \text { span }=0.9018 \\
\text { (micron) }\end{array}$ & $\begin{array}{l}x=0, y=0, z=0.198 \\
x \text { span }=0.2, y \operatorname{span}=2, z \\
\text { span }=0 \\
\text { (micron) }\end{array}$ & $\begin{array}{l}x=0, y=0, z=0 \\
x \operatorname{span}=2, y \operatorname{span}=2, \\
z \text { span }=0 \\
\text { (micron) }\end{array}$ \\
\hline \multirow{3}{*}{$\begin{array}{l}\text { Time } \\
\text { apodization }\end{array}$} & Apodization time $(\mathrm{fs})=500$ & Apodization time $(\mathrm{fs})=0$ & Apodization time $(\mathrm{fs})=0$ \\
\hline & $\begin{array}{l}\text { Apodization time width } \\
(\mathrm{fs})=100\end{array}$ & $\begin{array}{l}\text { Apodization time width } \\
(\mathrm{fs})=250\end{array}$ & $\begin{array}{l}\text { Apodization time width } \\
(\mathrm{fs})=250\end{array}$ \\
\hline & $\begin{array}{l}\text { Apodization freq width } \\
\text { (fs) }=4.412\end{array}$ & $\begin{array}{l}\text { Apodization freq. width } \\
\text { (fs) }=1.76\end{array}$ & $\begin{array}{l}\text { Apodization freq. width } \\
\text { (fs) }=1.76\end{array}$ \\
\hline
\end{tabular}

RESULTS AND DISCUSSION

Light absorption happened mainly in P3HT: PCBM layer. Absorption in P3HT: PCBM vs wavelength graph is calculated by changing period to diameter ratio and height. The thickness of the ITO and PEDOT: PSS are fixed to $178 \mathrm{~nm}$ and $50 \mathrm{~nm}$, respectively, and that of P3HT: PCBM is fixed to $193 \mathrm{~nm}$.

Fig. 5 shows the effect of height change on absorption enhancement of organic solar cell

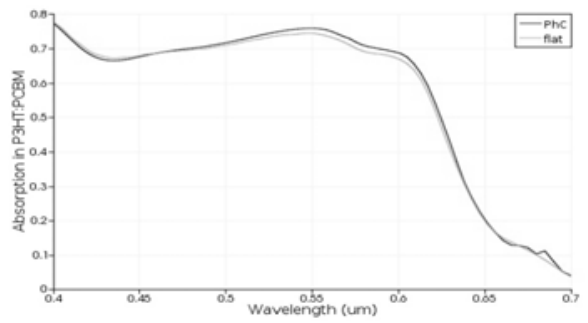

Fig. 5(a). Height of HLS is set to 0.03

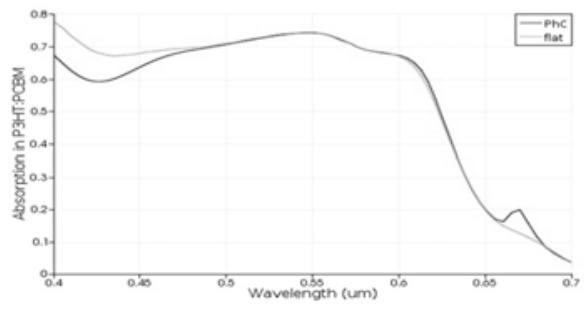

Fig. 5(c). Height of HLS is set to 0.13 micron respectively where $\mathrm{r} / \mathrm{a}$ ratio is 0.3 (Marko et al. 2001).

In Fig. 5(a), no significant change is observed between organic solar cell with photonic crystal structure and conventional flat solar cells. But in Fig. 5(b), there is a peak in higher wavelength region approximately at $674 \mathrm{~nm}$ where absorption ratio is 0.240 and also a slight decrease of absorption in lower wavelength region.

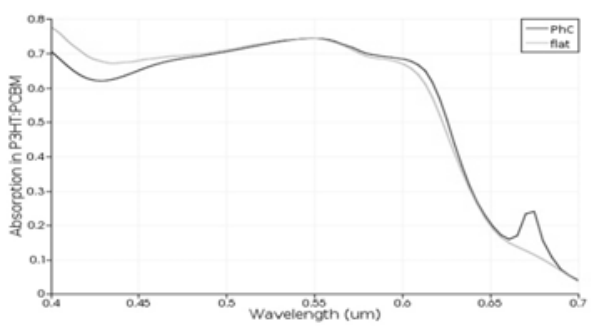

Fig. 5(b). Height of HLS is set to 0.11

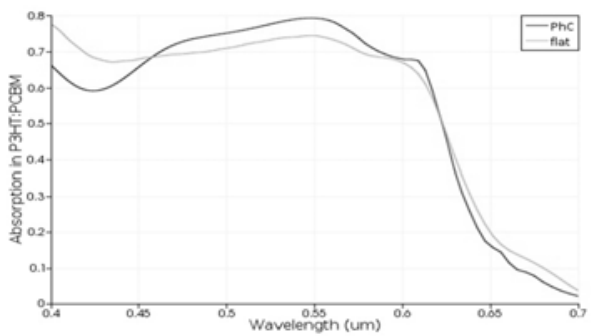

Fig. 5(d). Height of HLS is set to 0.21 


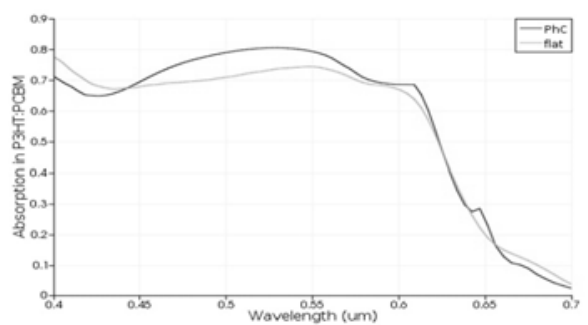

Fig. 5(e). Height of HLS is set to 0.29

A significant decrease of absorption in lower wavelength region which is 0.672 and the peak in the higher wavelength region at 669 $\mathrm{nm}$ begins to decrease and the absorption in the peak is 0.199 which is shown in Fig. 5(c). On the other hand, absorption in lower wavelength region (400 $\mathrm{nm}$ ) decreases to 0.661 and there is increase of absorption in middle wavelength region between $457 \mathrm{~nm}$ to $617 \mathrm{~nm}$ in Fig. 5(d). The highest absorption in the middle wavelength region is 0.79 which is found at $548 \mathrm{~nm}$.

Fig. 5(e) shows that absorption in lower wavelength region $(400 \mathrm{~nm})$ increases a bit. But the absorption in middle wavelength region widens more from $439 \mathrm{~nm}$ to $620 \mathrm{~nm}$. The highest absorption in the middle wavelength region is 0.805 which is found at $529 \mathrm{~nm}$. Besides, Fig. 5(f) shows that absorption in middle wavelength region begins to contract than before and absorption in lower wavelength start to increase. Absorption enhancement is seen between 437 to $582 \mathrm{~nm}$ and the highest absorption in the middle wavelength region is 0.788 which is found at $538 \mathrm{~nm}$.

Fig. 6 shows the effect of height on absorption enhancement of organic solar cell with photonic crystal when r/a ratio is fixed to 0.368 micron and 0.46 micron respectively where r/a ratio is 0.4 ( Emmanuel et al. 2009)

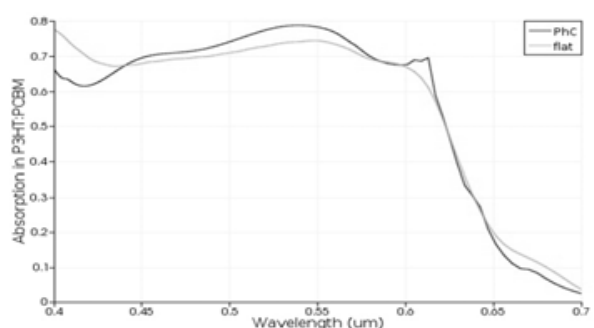

Fig. 5(f). Height of HLS is set to 0.37

In Fig. 6(a), there is no significant change is observed between organic solar cell with photonic crystal structure and conventional flat solar cells. But in Fig. 6(b), a peak is shown in higher wavelength region approximately in 674 $\mathrm{nm}$ wavelength where absorption ratio is 0.235 and also a slight decrease of absorption in lower wavelength region.

A significant decrease of absorption in lower wavelength region which is 0.571 and peak in the higher wavelength region almost disappears in Fig. 6(c). On the other hand, absorption in lower wavelength region (400 $\mathrm{nm}$ ) decreases to 0.547 and there is increase of absorption in middle wavelength region between $463 \mathrm{~nm}$ to $568 \mathrm{~nm}$ which is shown in Fig. 6(d). The highest absorption in the middle wavelength region is 0.79 which is found at $532 \mathrm{~nm}$.

Fig. 6(e) shows that absorption in lower wavelength region $(400 \mathrm{~nm})$ increases a bit. But the absorption in middle wavelength region widens more from $463 \mathrm{~nm}$ to $575 \mathrm{~nm}$. The highest absorption in the middle wavelength region is 0.81 which is found at $526 \mathrm{~nm}$. Besides, Fig. 6(f) shows that absorption in middle wavelength region begins to contract than before and absorption in lower wavelength start to increase. Absorption enhancement is seen between 

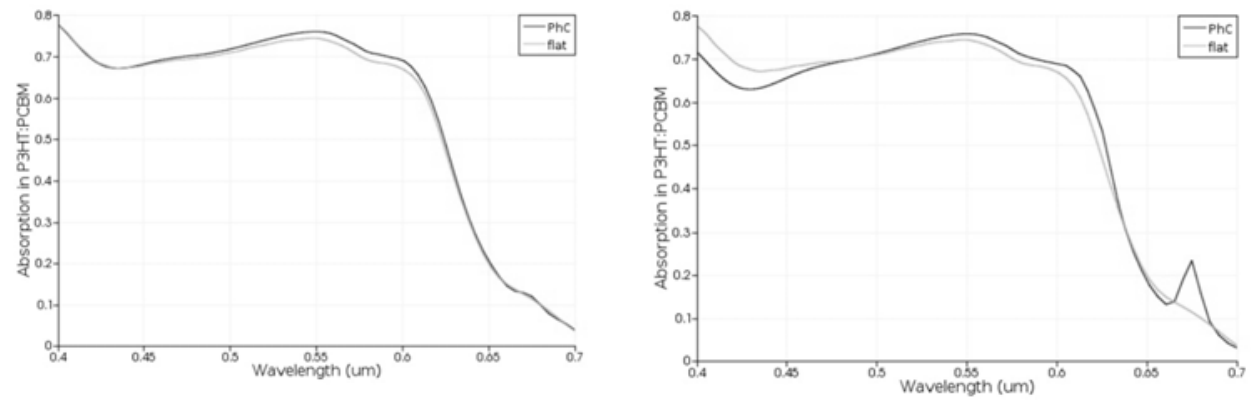

Fig. 6(a). Height of HLS is set to 0.01

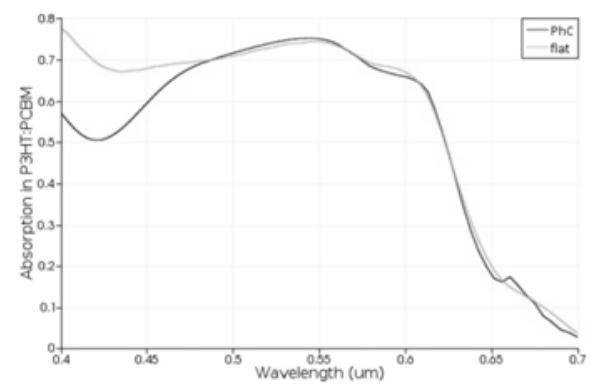

Fig. 6(b). Height of HLS is set to 0.09

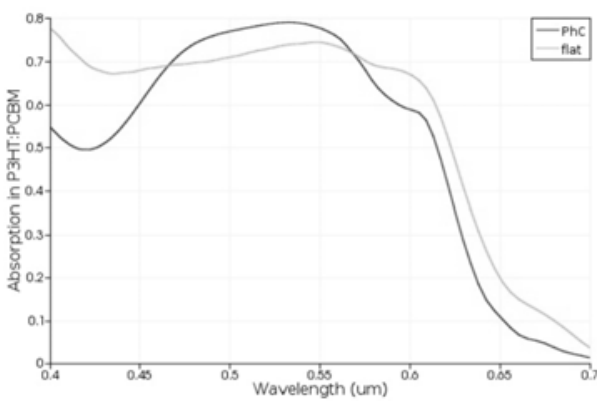

Fig. 6(c). Height of HLS is set to 0.14

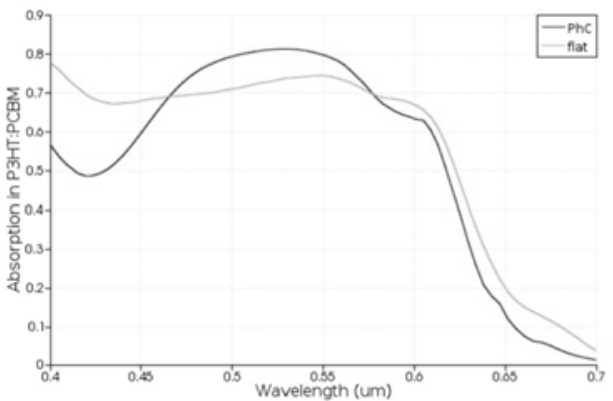

Fig. 6(e). Height of HLS is set to 0.26

439 to $551 \mathrm{~nm}$ and the highest absorption in the middle wavelength region is 0.78 which is found at $523 \mathrm{~nm}$.

Fig. 7 shows the effect of height on absorption enhancement of organic solar cell with photonic crystal when the period and diameter is fixed to 0.184 micron and 0.46 micron respectively where r/a ratio is 0.2 (Masud et al. 2012).

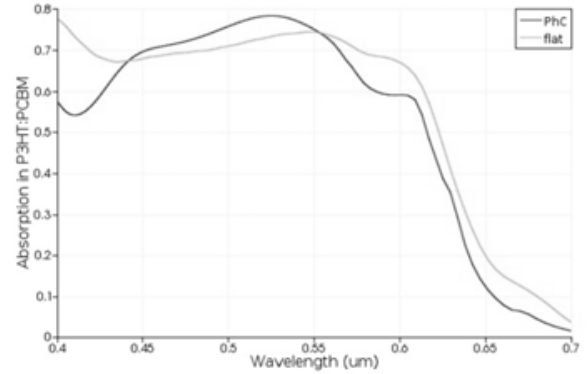

Fig. 6(f). Height of HLS is set to 0.36

In Fig. 7(a), there is no significant change is observed between organic solar cell with photonic crystal structure and conventional flat solar cells. But in Fig. 7(b), a peak in higher wavelength region approximately in $679 \mathrm{~nm}$ wavelength where absorption ratio is 0.179 and also a slight decrease of absorption in lower wavelength region. 


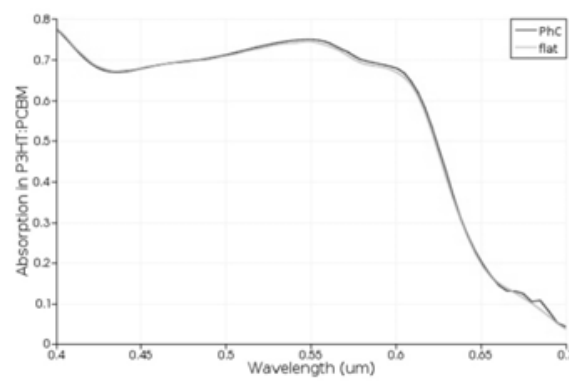

Fig. 7(a). Height of HLS is set to 0.04 .

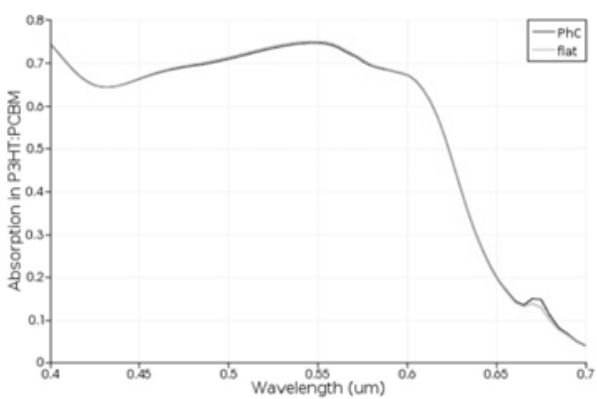

Fig. 7(c). Height of HLS is set to 0.15 .

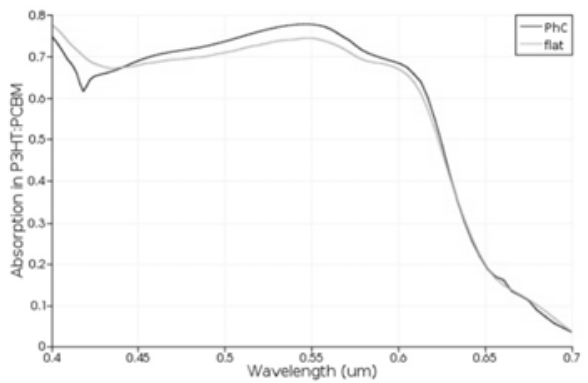

Fig. 7(e). Height of HLS is set to 0.34 .

Fig. 7(c) shows that no change of absorption compared to flat solar cell in lower wavelength region. Peak in the higher wavelength region almost disappears. Besides, in Fig. 7(d), absorption in lower wavelength region (400 $\mathrm{nm}$ ) decreases to 0.749 and there is increase of absorption in middle wavelength region between $450 \mathrm{~nm}$ to $625 \mathrm{~nm}$. The highest absorption in the middle wavelength region is 0.767 which is found at $551 \mathrm{~nm}$.

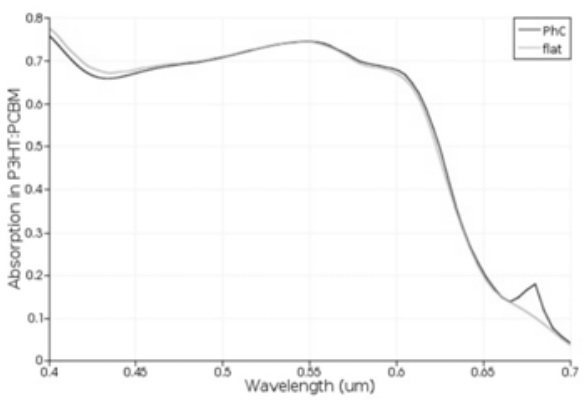

Fig. 7(b). Height of HLS is set to 0.10 .

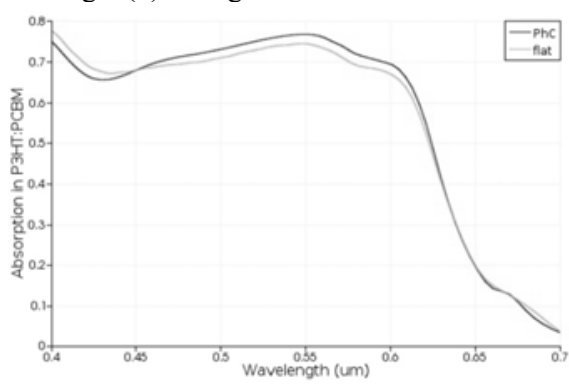

Fig 7(d). Height of HLS is set to 0.21 .

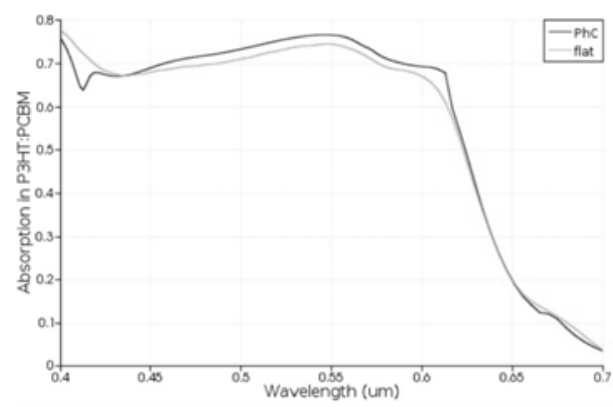

Fig. 7(f). Height of HLS is set to 0.40 .

Absorption in lower wavelength region at $417 \mathrm{~nm}$ decreases to 0.615 . The absorption in middle wavelength region widens more from $439 \mathrm{~nm}$ to $625 \mathrm{~nm}$ which is shown in Fig. 7(e). The highest absorption in the middle wavelength region is 0.778 which is found at $545 \mathrm{~nm}$. On the other hand, in Fig. $7(\mathrm{f})$, absorption in middle wavelength region begins to contract than before and sudden decrease of absorption in lower wavelength 
shifts at $410 \mathrm{~nm}$. Absorption enhancement is seen between 437 to $620 \mathrm{~nm}$ and the highest absorption in the middle wavelength region is 0.765 which is found at $548 \mathrm{~nm}$.

These graphs compare absorption enhancements between organic solar cell with photonic crystal structure (aluminum oxide as photonic crystal) and conventional silicon flat solar cells. The three groups of graphs show the effect of height from these graphs, it can be seen that the absorption at the longer wavelength can be enhanced by photonic crystal. Here, the period, the diameter and the height of the $\mathrm{PC}$ are fixed to $\mathrm{P}=460 \mathrm{~nm}, \mathrm{D}=$ $300 \mathrm{~nm}$. and $\mathrm{h}=120 \mathrm{~nm}$, respectively and the thickness of the $\mathrm{Al}_{2} \mathrm{O}_{3}$ is set to $\mathrm{t}=150 \mathrm{~nm}$. Users can optimize the design by the built-in optimization algorithm.

\section{CONCLUSION}

It is concluded that the photonic crystal structures of aluminum oxide can be modeled as a photoactive layer and analyzed using Finite Difference Time Domain to determine and observe the absorption enhancement and the effects of changes in height with different fixed periodicity and diameter. As height is increased with constant period and diameter, absorption at lower wavelength region decreased a lot and absorption in middle wavelength region approximately tends to reverse. The changes in absorption also happens because of guided modes created by aluminum oxide. Different material is taken as photonic crystal and aluminum oxide seems to achieve the most favourable results. Silicon dioxide (Khai Q. et al. 2015) shows almost similar absorption enhancement compared to aluminum oxide.

\section{REFERENCES}

Alias M. S., S.A. Kamaruddin, N. Nafarizal, M.Z. Sahdan. 2014. 'Performance of Inverted Organic Solar Cell using Different Metal Electrodes' 2014 IEEE International Conference on Semiconductor Electronics (ICSE2014), Kuala Lumpur, Malaysia

https://doi.org/ 10.1109/SMELEC.2014.6920886

Balderramaa, V.S., M. Estradab, P. Formentina, B. Iñigueza, J. Ferré-Borrulla, J. Pallarésa, J. C. Nolascoa, E. Palomaresc, A. Sánchezc and L.F. Marsala. 2011. 'Performance and degradation of organic solar cells with different P3HT:PCBM[70] blend composition', Proceedings of the 8th Spanish Conference on Electron Devices, CDE', Palma de Mallorca, Spailn

https://doi.org/ 10.1109/SCED.2011.5744224

Bozzola Angelo, Marco Liscidini and Lucio Claudio. 2012. 'Light Trapping in Thin Film Solar Cells with Sub-Wavelength Photonic Crystal Patterns', 14th International Conference on Transparent Optical Networks (ICTON), Coventry, UK

https://doi.org/10.1109/ICTON.2012.6254404

Cheyns, D., B.P. Rand and P. Heremans. 2010. Organic tandem solar cells with complementary absorbing layers and a high open-circuit voltage. Appl. Phys. Lett. 97 doi: $10.1063 / 1.3464169$

Deepti Dhuriya, Brijesh Kumar and R. K. Chauhan. 2016. 'Recent Advancement in Organic Solar Cells and Comparison between Various Structures', International Conference on Emerging Trends in Communication Technologies (ETCT), Dehradun, India. https://oi.org/10.1109/ ETCT.2016.7882960

Drouard Emmanuel, Guillaume Gomard, Xianqin Meng, Ounsi El Daif, Anne KaminskiCachopo, Alain Fave, Mustapha Lemiti and Christian Seassal. 2010. 'Photonic Crystal Based Structures for Ultra-Thin Film Solar Cells' 12th International Conference on Transparent Optical Networks, June-July 2010, Munich, Germany, https://doi.org/ 10.1109/ICTON.2010.5548995

Drouard Emmanuel, Yeonsang Park, Ounsi EI Dair, XavierLetartre, Pierre Viktorovitch, Alain Fave, Anne Kaminski. 2009. Mustapha 
Lemitt and Christian Seassal. 'Photonic crystal silicon based structures for thin film solar cell', Asia Communications and Photonics conference and Exhibition (ACP), Shanghai, China, https://doi.org/10. 1364/ ACP.2009.ThHH2

Joannopoulos, J. D., S. G. Johnson, J. N. Winn and R. D. Meade. 2008. "Photonic Crystals: Molding the Flow of Light", Princeton University Press, pp.4. http://ab-initio.mit. edu/ book/photonic-crystals -book.pdf

Karim Nusrat, Farha Islam Mime and Md. Rafiqul Islam Ibrahim Mustafa Mehedi. 2017. 'Tandem Organic Solar Cells with Improved Efficiency', International Conference on Electrical, Computer and Communication Engineering (ECCE), Cox's Bazar, Bangladesh https://doi.org/10.1109/ECACE 2017.7913016

Kerns David and Melvin Calvin. 1958. 'Photovoltaic Effect and Photoconductivity in Laminated Organic Systems', Journal of Chemical Physics 29:950-951 https://doi.org/ 10.1063/1.1744619

Khai Q. Le, Matthew Nixon, Jing Bai and Khai Q. Le. 2015. Matthew Nixon, and Jing Bai 'Calibrated Dielectric Fiber Arrays for Light-Trapping Enhancement in Organic Solar Cells', IEEE Journal Of Photovoltaics, 5(4). https://doi.org/10.1109/JPHOTOV 2015.2427575

Knowledge base, Lumerical Solutions Inc. https://kb.lumerical.com/en/solar_cells orga nic.html

Ko Doo-Hyun, John R. Tumbleston,Lei Zhang, Stuart Williams, Joseph M. DeSimone, Rene Lopez, and Edward T. Samulski. 2009. 'Photonic Crystal Geometry for Organic Solar Cells', Nano Letters 9(7): 2742-2746 DOI: $10.1021 / \mathrm{n} 1901232 \mathrm{p}$

Marko Lonc`ar, Jelena Vuc'kovic' and Axel Scherer. 2001. 'Methods for controlling positions of guided modes of photoniccrystal waveguides' Journal of the Optical Society of America B, 18(9): 1362-1368. https://doi.org/10.1364/JOSAB.18.001362

Mutitu1 James G., Shouyuan Shi1, Allen Barnett'. Christiana Honsberg2 and Dennis W. Prather. 2009. 'Llght Trapping Designs For Thin Silicon Solar Cells Based On Photonic Crystal And Metallic Diffractive Grating
Structures', 34th IEEE Photovoltaic Specialists Conference (PVSC), Philadelphia, PA, USA, https://doi.org/ 10.1109/ PVSC.2009.5411616

Omar Ramírez, Víctor Cabrera and Luis Martín. 2013. 'Optimum ratio of electron-to-hole mobility in P3HT:PCBM organic solar cells', Omar Ramírez, Víctor Cabrera, Luis Martín, 'Optimum ratio of electron-to-hole mobility in P3HT:PCBM organic solar cells', Optical and Quantum Electronics, 46(10): 1291-1296. https://doi.org/10.1007/ s11082-013-9855-1

Parvez Arnob Md. Masud, A.B.M. Hasan Talukder, Md. Omar Faruk, Tamanna Afrin Tisa, Zahid Hasan Mahmood. 2012. 'Design and Simulation of an Optical Wavelength Division Demultiplexer Based on the Photonic Crystal Architecture', International Conference on Informatics, Electronics \& Vision (ICIEV), Dhaka, Bangladesh, https://doi.org/ 10.1109/ICIEV.2012.6317380

Peres Léo, Valérie Vigneras and Sophie Fasquel. 2014. Light trapping efficiency of organic solar cells with large period photonic crystals, Optical Society of America (OSA), 22(S35) : A1229-A1236. https://doi.org/10. 1364/OE.22.0A1229

Prodhan MMH, ABMH Talukder, MF Huq, SK Aditya. 2017. 'Design, Analysis and Performance Study of PV-Wind-Diesel Generator Hybrid Power System for a Hilly Region Khagrachari of Bangladesh', Journal of Scientific Research 9(1): 57-66. http://dx.doi.org/10.3329/jsr.v1i1.29480

Rahman Zurianti A., Ahmad Shuhaimi, Mohamad Rusop and Khaulah Sulaiman. 2012. 'Electronic Properties and Electrical Characteristics of Modified PEDOT:PSS as a Buffer Layer in Organic Solar Cell', IEEE international conference on Electronics design, Systems and Applications (ICEDSA), Kuala Lumpur, Malaysia https://doi.org/ 10.1109/ICEDSA.2012.6507796

Schmidt, M., G. Ulisse and C. Ciceroni. 2015. 'Nanopatterning of P3HT:PCBM for organic solar cell realization' IEEE 15th International Conference on Nanotechnology (IEEE-NANO), Rome, Italy. https://doi.org/ 10.1109/ NANO. 2015.7388890

Spanggaard Holger, Frederik C. Krebs. 2004. 'A brief history of the development of organic 
and polymeric photovoltaics', Solar Energy Materials and Solar Cells, Elsevier 83(2-3) : 125-146.

https://doi.org/10.1016/j.solmat.2004.02.021

Tang, C.W. 1986. 'Two-layer organic photovoltaic cell', Appl. Phys. Lett. 48:183185. doi: $10.1063 / 1.96937$

Vikram, L. Dalal, Robert Mayer, Joydeep Bhattacharya and Mehram Samiee. 2012. 'Stability of Organic Solar Cells', IEEE International Reliability Physics Symposium (IRPS), Anaheim, CA, USA, https://doi.org/ 10.1109/IRPS.2012.6241829

Woods, K., F. Ashrafzadeh and H. Rathnayake. 2013. 'Organic Solar Cell Energy Harvesting, Control, Optimization, and Commericalization - Challenges and
Opportunities', 4th IEEE International Symposium on Power Electronics for Distributed Generation Systems (PEDG), 2013.http://ieeexplore.ieee.org/xpls/icp.jsp?a rnumber $=6785614$

Yeh Naichia and Pulin Yeh. 2013. 'Organic Solar Cells: Their Development and Potentials', Renewable and Sustainable Energy Reviews, Elsevier 21: 421-431 https://doi.org/10.1016/ j.rser.2012.12.046

You J., Dou L.D., Yoshimura K., Kato T., Ohya K., Moriarty T., Emery K., Chen C.C., Gao J., Li G., et al. 2013. A polymer tandem solar cell with $10.6 \%$ power conversion efficiency. Nat. Commun. 4 doi: 10.1038/ ncomms2411

(Received revised manuscript on 27 March, 2018 